\title{
The Effect of Two-Stage Acid Treatment on Surface Behavior and Improvement of Bioactivity of Nitinol Alloy
}

\author{
Nima Norouzi ${ }^{1, * \text { (D) }}$, Zahra Nouri ${ }^{2}$ (D) \\ 1 School of Energy and Physics, Amirkabir university of technology (Tehran Polytechnic); nima1376@aut.ac.ir (N.N.); \\ 2 School of Medicine, Tehran University of Medical Sciences, Tehran, Iran; zn65133@gmail.com (Z.N.); \\ * Correspondence: nima1376@aut.ac.ir;
}

Received: 17.10.2020; Revised: 10.11.2020; Accepted: 11.11.2020; Published: 14.11.2020

\begin{abstract}
Surface properties, including morphology, submicron morphology, and surface chemistry, are essential factors that affect the quality and manner of biological responses at the site of tissue contact with the implant, affecting the bone healing process. In this in vitro study, morphology and biocompatibility of nitinol (NiTi) memory alloy surfaces mechanically polished and modified with a chemical solution consisting of three types of acid $\left(\mathrm{HCl}-\mathrm{HF}-\mathrm{H}_{3} \mathrm{PO}_{4}\right)$ and then chemical operations in solution $\left(\mathrm{HNO}_{3}\right.$ and $\left.\mathrm{HCl}\right)$ with a Volumetric scale of $1: 1$ and examined at ambient temperature. 75 samples were used for surface chemical modification, biological evaluations, and surface roughness, and also 9 samples as control. Scanning electron microscopy (SEM), atomic force microscopy (AFM), and nitinol alloy (NiTi) surface roughness measurements were performed to analyze the surfaces. Besides, MG-63 cells were cultured on different nitinol alloy levels to evaluate adhesion and cell growth and proliferation. Data were analyzed using t-test and one-way analysis of variance. The results show that the chemical surface modification operation with two-stage acid solution had a higher roughness compared to the unmodified surfaces and the surface chemical modification operation with the acidic solution with an only solution consisting of $\left(\mathrm{HCl}-\mathrm{HF}-\mathrm{H}_{3} \mathrm{PO}_{4}\right)$. Cell culture evaluations also showed that the two-stage modified nitinol levels showed significant cell adhesion and significant growth and proliferation compared to the tertiary acid-modified and unmodified levels. The surface chemical modification method for nitinol alloy can change the surface chemistry and change the surface morphology and create sub-micron scale roughness. This can increase the connectivity of the implant tissue and reduce the toxic effect of nickel.
\end{abstract}

Keywords: nitinol alloy; chemical surface modification; cell culture; acid etching; medical material.

(C) 2020 by the authors. This article is an open-access article distributed under the terms and conditions of the Creative Commons Attribution (CC BY) license (https://creativecommons.org/licenses/by/4.0/).

\section{Introduction}

Nitinol alloys with atomic percentages of nickel and titanium can be used as metal implants in orthopedics; This is due to their super-elastic properties and corrosion resistance [1-3]. Despite the satisfactory clinical use of nitinol alloys in some conditions, the presence of high nickel in the alloy is very worrying for their biocompatibility. Activity in nitinol alloys can be achieved by various methods such as plasma spraying, hydrothermal treatment, ionizing precipitation, sol-gel method, and simple chemical preparation for the surface such as the use of alkaline solutions (sodium hydroxide) or surface chemical Acid solution as well as oxidation operation with hydrogen peroxide solution $\left(\mathrm{H}_{2} \mathrm{O}_{2}\right)[3,4]$.

The alkaline operation produces a layer of sodium titanate on the surface of titanium $[5,6]$, while operation with hydrogen peroxide forms a gel layer of titanium on the surface [7]. 
This is while both sodium titanium and titania gel layers can precipitate apatite-like bone. They are on their own in the laboratory and clinical environment, and from this perspective, they are considered bioactive $[1,8]$.

Alkaline operations have also been suggested to be effective in the bioactivation of other biomaterials' surfaces such as tantalum. It has also been suggested that modification of the titanium surface with acid etching can positively affect the integrity of implants in bone [79]. In one study, bone behavior was compared to the biomaterial surface (whose surface was machined and then modified using $\mathrm{HCl}-\mathrm{H}_{2} \mathrm{SO}_{4}$ solution). The surface is chemically acidified with the solution) indicates an increase in biocompatibility in the implant [9].

It has been purely commercial, as evidenced by this [7, 10]. However, in the case of nitinol alloys, in some cases, the presence of high nickel in the alloy is problematic for their biocompatibility [1,2]. Nickel is effective in causing allergic behaviors and clinical toxicities [2]. Several researchers have reported that if nickel ions are released from the alloy surface in contact with the biological body fluid, this can cause serious problems for the tissue around the implant $[2,11]$. Besides, it has been reported that alloy surface modification with The use of surface chemicals can prevent the release of the element nickel by forming a homogeneous and stable layer of titanium oxides; The result is very effective in improving the biocompatibility of the material $[2,12]$. Also, in a study to create bioactivity on the surface, hydrochloric acid and hydrogen peroxide have been used [13]. This study aimed to investigate the surface behavior of nitinol alloy in the presence of strong acidic solutions and the effect of this operation on increasing the biocompatibility of the surface of this alloy. In addition, this study uses a new idea for the presence of calcium on the surface of the alloy, which is also considered as a method of biological imitation [6-8, 11-13].

\section{Materials and Methods}

Samples of nitinol alloy (50.5\% atomic nickel) in the form of a disc with a diameter of $5 \mathrm{~mm}$ and a thickness of $1 \mathrm{~mm}$ were selected as 75 samples for surface chemical modification, biological evaluations, and surface roughness, as well as nine samples as control. Then, the samples' surface was subjected to mechanical polishing using sanders with numbers 280, 320, 500,600 , respectively [6]. After performing mechanical polishing operations to remove surface contaminants and obtain a clean surface for surface correction operations, The samples were washed in an ultrasonic chamber. In this regard, mechanically polished samples with $40 \%$ by volume of sodium hydroxide $(\mathrm{NaOH})$ and $50 \%$ by volume of nitric acid $\left(\mathrm{HNO}_{3}\right)$ in an ultrasonic chamber (ATSmall, Iran) with a frequency of $40 \mathrm{~Hz}$ (240 watts) and a mechanical timer (heater 200 Watts) for 15 minutes, washed. Then, by draining the washing solution, the samples were rewashed with distilled water in an ultrasonic chamber and finally kept at $70^{\circ} \mathrm{C}$ in ethanol alcohol at room temperature $[14,15]$.

The samples of the cleaned memory alloy, according to Table 1, were placed in acidic solutions, and the surface modification operation was performed on them by chemical method. It should be noted that the choice of acid type and acidic solution conditions goes back to the previous study of the authors in the field of modification of biomaterial levels [16-18].

Each of the above acid solutions was prepared in a volume of $10 \mathrm{cc}$ in plastic humans and stored for one day. Then 9 samples of nitinol were selected for each of the surface chemical modification operations, and also 9 samples were considered as controls. NiTi samples were then placed in each of the acidic solutions for 10 minutes for surface chemical correction and 20 hours for chemical treatment (with a minimal amount of sodium chloride salt to form 
complex compounds and accelerate the corrosion reaction on the surface of nickel-containing alloys), which were exposed to ambient temperature. After chemical treatment of the surface, the samples were taken out of solutions with an absolute concentration and immediately washed with distilled water and then with acetone in an ultrasonic chamber. Then, using an electric dryer, the samples' surface was dried in normal air and then in a desiccator. Were placed to perform the necessary surveys on their surface.

To study the samples' surface morphology, scanning electron microscopy (Sem, VegaTescan) with a voltage of $20 \mathrm{kV}$ was performed. Besides, atomic force microscopes (Auto Probe, Scientific Park Instruments, USA, Afm) were used to examine the morphology and surface roughness.

Osteogenic cells (MG-63) amplified using culture medium (DMEM, GIBCO, Scotland) and addition of $10 \%$ fetal, fetal serum (FCS (Seromed, Germany)) with antibiotics of $100 \frac{\mathrm{IU}}{\mathrm{ml}}$ penicillin and $100 \frac{\mu g}{m l}$ streptomycins (Sigma, USA) To prepare the cell for two types of evaluation of adhesion and cell growth and proliferation $[9,19]$ :

MTT method was used to evaluate the rate of cell growth and proliferation [20, 21]. The MTT method is commonly used to evaluate cell survival. The yellow salt is tetrazolium, which is absorbed by the cells and causes the formation of insoluble purple crystals. This method is based on the activity of the cellular mitochondrial enzyme. Accordingly, two periods of 3 and 6 days were considered to evaluate the rate of cell growth and proliferation on titanium samples' surface. Besides, $104 \frac{\mathrm{Cell}}{\mathrm{cm}^{2}}$ were used on the surface of nitinol samples. Therefore, according to the repetition of experiments up to 3 times and the times mentioned above, 696 well 96-pellet piles were selected, in each of which there was a group of selected groups A to D. To prepare an MTT solution with a concentration of $5 \frac{\mathrm{mg}}{\mathrm{ml}}, 50 \mathrm{mg}$ of MTT powder in $10 \mathrm{mg}$ of PBS was dissolved in 0.15 Molar and diluted 10 times with PBS when used in staining to obtain a solution of $0.5 \frac{\mathrm{mg}}{\mathrm{ml}}$ MTT.

Table 1. Conditions for surface chemical modification operations on memory alloy groups.

\begin{tabular}{|c|c|c|}
\hline Sample & Acid solution conditions & Chemical operations \\
\hline $\mathbf{A}$ & Control & Control \\
\hline $\mathbf{B}$ & $\begin{array}{l}80 \% \text { hydrochloric acid }-10 \% \text { fluoric acid- } 10 \% \\
\text { phosphoric acid (10 minutes, ambient temperature) }\end{array}$ & No chemical operations \\
\hline $\mathbf{C}$ & $\begin{array}{l}80 \% \text { hydrochloric acid }-10 \% \text { fluoric acid- } 10 \% \\
\text { phosphoric acid (10 minutes, ambient temperature) }\end{array}$ & $\begin{array}{l}56 \% \text { nitric acid (20 hours, at room } \\
\text { temperature) }\end{array}$ \\
\hline D & $\begin{array}{l}80 \% \text { hydrochloric acid - } 10 \% \text { fluoride acid - } 10 \% \\
\text { phosphoric acid - } 1.7 \mathrm{~g} \text { of calcium fluoride }(10 \\
\text { minutes, ambient temperature) }\end{array}$ & No chemical operations \\
\hline $\mathbf{E}$ & $\begin{array}{l}80 \% \text { hydrochloric acid - } 10 \% \text { fluoride acid - } 10 \% \\
\text { phosphoric acid - } 1.7 \mathrm{~g} \text { of calcium fluoride }(10 \\
\text { minutes, ambient temperature) }\end{array}$ & $\begin{array}{l}\text { Nitric acid } 56 \%+\text { hydrochloric acid } \\
37 \% \text { in volume ratio }(1: 1),(20 \text { hours, } \\
\text { at room temperature })\end{array}$ \\
\hline
\end{tabular}

It should be noted that after preparing PBS, the solution was autoclaved. After incubation of MG-63 cells on the surfaces at intervals of 3 and 6 days, plates incubated at $37^{\circ}$ $\mathrm{C}$ and $5 \%$ carbon dioxide were stained with $0.5 \frac{\mathrm{mg}}{\mathrm{ml}}$ MTT solution. After 3 to 5 hours of incubation at $37^{\circ} \mathrm{C}$, the cell supernatant was removed, and $200 \mu \mathrm{l}$ of isopropanol solution (Merck, Germany) was added to the wells. The plates were placed on a shaker for 10 to 15 minutes. A microtiter reader then read the relevant plates at $570 \mathrm{~nm}[23,24]$. 
Trypan Blue method was used for cell adhesion test. In this method, living cell membranes do not allow non-electrolyte dyes to enter the cell, but dead cells stain well. By adding trypan blue solution to $0.15 \mathrm{M}$ PBS and then placing it on cultured surfaces in plate wells, the dead cells are stained and can be distinguished from the living (colorless) cells. Then, with the help of a histometer (neobar slide), the number of stained cells (dead) and the number of living cells (without color) are determined [25]. To test cell adhesion, 6000 cells were placed on the surface of each sample (to reach The desired amount was placed in an incubator for culture and cultured on the surface of nitinol samples for 16 hours.

One-way analysis of variance and Tukey test were used to analyze the results of surface roughness and biological evaluations. The significance level in the tests was considered 0.05.

\section{Results and Discussion}

Figure 1 shows an electron microscope image of a mechanically polished nitinol surface. Examining this shape, it can be seen that the surface has grooved and parallel lines. (Figure a-1). When the surface of a mechanically polished memory alloy is immersed in a solution of $80 \%$ hydrochloric acid, $10 \%$ fluoric acid, $10 \%$ phosphoric acid for 10 minutes at ambient temperature, this acidic solution has little effect on the formation of surface porosity on the alloy ( Figure b-1). The image also shows grooves due to mechanical polishing and surface cracks due to acid corrosion. Therefore, this acidic solution can not create micron-sized cavities on the surface with the conditions mentioned above. Figure (c-1) shows the memory alloy's surface after being immersed in the $\mathrm{C}$ group solution. Also, the created cavities are almost regular and follow the spherical geometric shape (spherical porosity). The placement of nitinol in a tertiary acidic solution with the formation of biological groups on the surface (calcium fluoride) is shown in figure (d-1), which shows surface cavities smaller in size than chemical treatment with nitric acid. Besides, in some areas, the surface is not affected by the acidic solution. As a result, no reference surface texture is created. Figure (e-1), the surface modification operation of nitinol alloy under the conditions of $80 \%$ hydrochloric acid, $10 \%$ fluoric acid, $10 \%$ phosphoric acid, $1.7 \mathrm{~g}$ of calcium fluoride (10 minutes, ambient temperature), and then chemical treatment with a solution of nitric acid 56 The percentage shows 37\% hydrochloric acid in a volume ratio of 1: 1 (20 hours, at room temperature). Examination of this form reveals the presence of wrinkles and loss of surface layers of nitinol alloy, which is due to the high corrosivity of the acidic solution. Also, the surface energy is very high under these conditions; So that subsequent surface operations eliminate the micropores created under the action of the tertiary acidic solution, and the surface is smoothed.

To study further, in addition to scanning electron microscopy, surface morphology was evaluated using AFM [1] atomic force microscope analysis, in which case RMS and Ra, which represent surface roughness, were calculated using this analysis. In figure (2-a-e), atomic force microscopy images show the surface morphology of the polished and modified surface of the NiTi memory alloy in two-dimensional and three-dimensional modes. Examination of Figure (2-a) shows that the surface of the nitinol alloy contains lines and grooves parallel to the shape resulting from mechanical polishing operations. Besides, this image shows the application of mechanical polishing operations, creating a surface with minimal roughness and depressions and protrusions on the micron scale. In contrast, performing this operation can cause the surface to shrink locally to less than a micron-scale in some areas. The AFM image of the nitinol alloy surface is shown in figure (b-2) after being immersed in an acidic solution of $80 \%$ hydrochloric 
acid, 10\% fluoric acid, and 10\% phosphoric acid. Examination of Figure (b-2) shows that the morphology of the surface has not been significantly affected by acidic chemical operations.
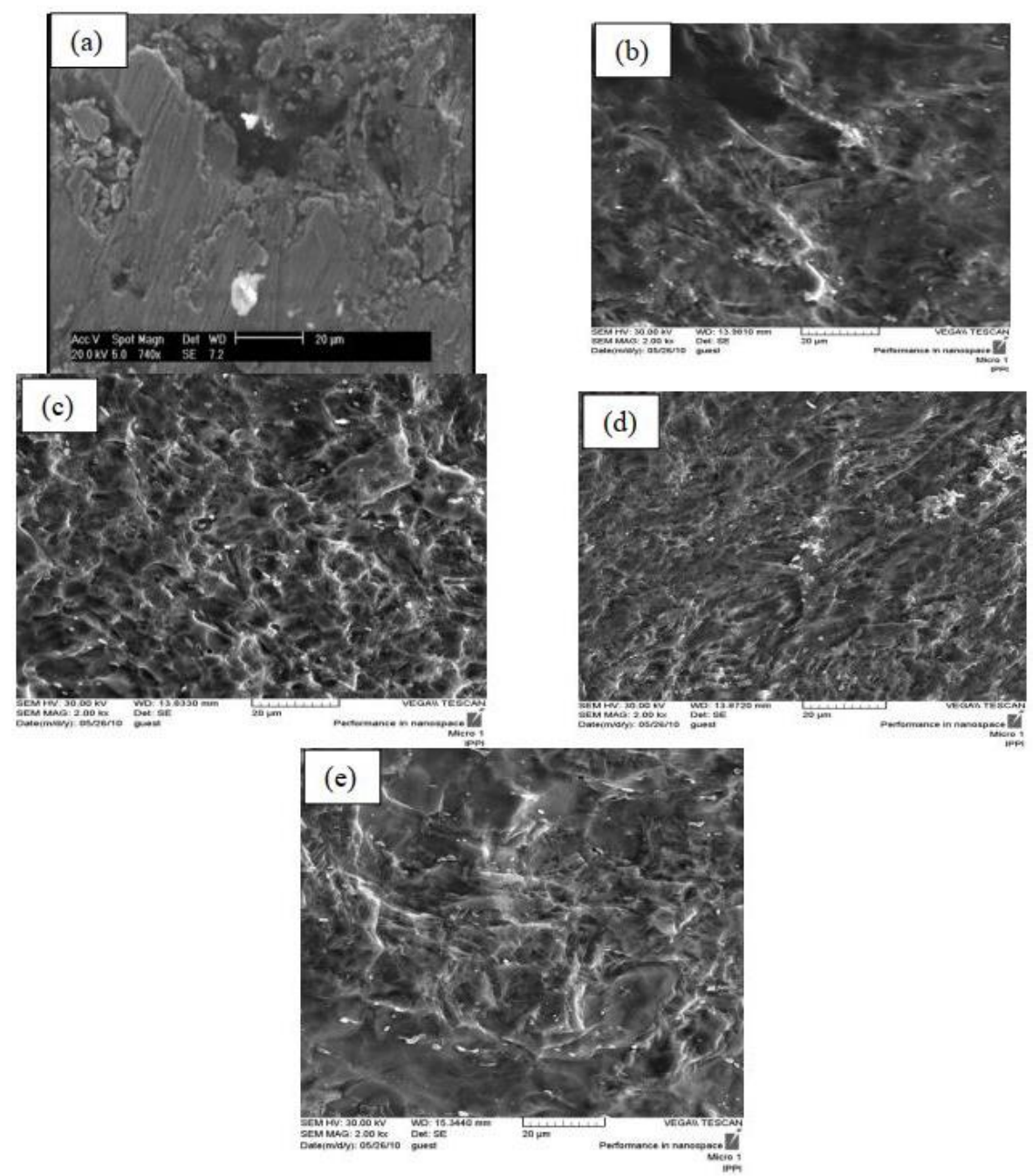

Figure 1. Scanning electron microscope image of mechanically polished nitinol surface modified with a): operation A, b) operation B, c): Operation C, d) Operation D, e) Operation E. Source: Labrotuary of nanoscience, Tehran University

Also, the lines and grooves caused by the surface polishing operation have been eliminated in the previous stage, and irregular surface porosities have been created in a limited way, which is very clear in the image. By observing the figure (c-2), the surface is affected and created on the depression and protrusion surface. This factor has increased surface roughness. Figure (d-2) shows the morphological results of a nitinol alloy's surface in a tertiary acidic solution with the formation of biological groups on the surface (calcium fluoride). This operation's AFM image shows that the acidic solution had an intense corrosion concentration in the areas inside the surface cavities; So that tiny cavity of less than micron-scale are created on the surface.

It should be noted that the presence of calcium fluoride has affected the corrosion potential of the tertiary acidic solution. The cavities created are smaller in size than chemical operations with nitric acid (Figure (c-2)). However, this indicates that the surface has not been affected by the acidic solution in some areas. Figure (2-e), atomic force microscope image of nitinol alloy surface after surface modification under $80 \%$ hydrochloric acid, $10 \%$ fluoric acid, $10 \%$ phosphoric acid, $1.7 \mathrm{~g}$ of calcium fluoride (10 minutes, ambient temperature) and then 
operation Chemical with a solution consisting of $56 \%$ nitric acid, $37 \%$ hydrochloric acid in a volume ratio of 1: 1 (20 hours, at room temperature). This shape reveals the presence of wrinkles and loss of surface layers, which can be due to the acidic solution's high corrosivity. This was also the case with the electron microscope image. The surface's elevation is very high in these conditions, and all parts of the alloy surface are affected. Also, the effect of hydrochloric acid in the chemical operation stage has been able to change the corrosion conditions of the surface. The surface texture is weak in terms of the presence of cavities in the shape of a hemisphere and the same size. Morphology is a combination of tiny cavities and peeled surfaces with high elevation.
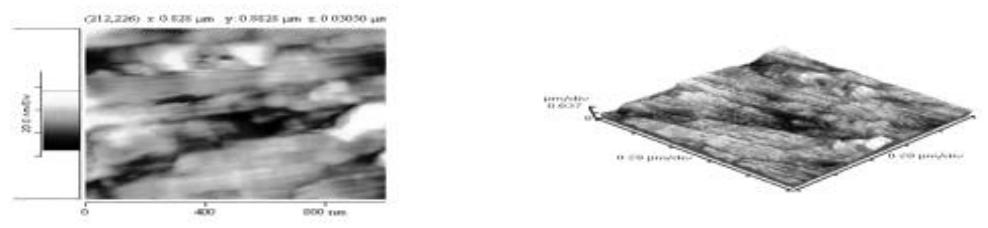

(a)
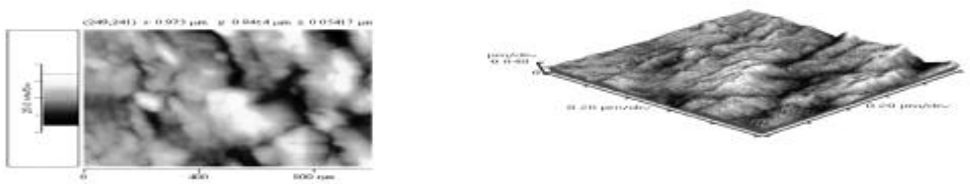

(b)

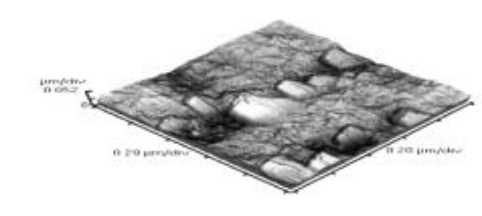

(c)
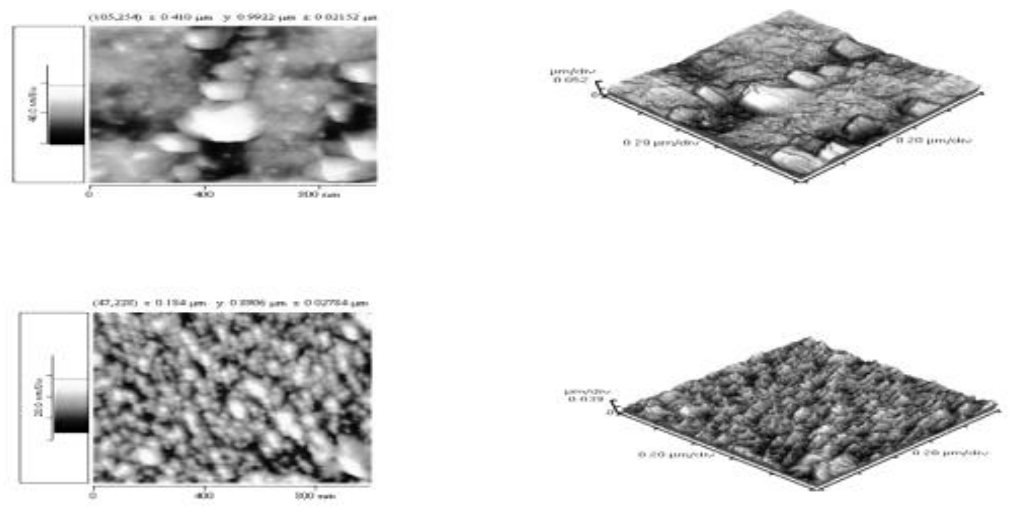

(d)
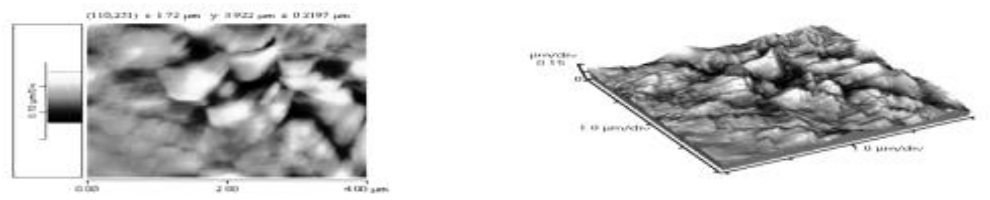

(e)

Figure 2. Atomic force microscope image of polished and modified nitinol surface with a): operation A, b) operation B, c): operation C, d) Operation D, e) Operation E. Source: Labrotuary of nanoscience, Tehran University

Figure 3- (a-b) shows the mean values of surface roughness (Ra) and the amount of surface roughness (RMS) of mechanically polished and chemically modified memory alloy surfaces. In this regard, the highest surface roughness is related to the surface operation related to operation E execution. As can be seen from atomic force microscope images, the nitinol memory alloy's surface morphology has been intricately intertwined with the E operation. Besides, the elevation and elevation of the surface, in this case, are higher than in other groups (A-D). Group C, which had regular porosity (Figure 2-c) and nitric acid, was used for subsequent chemical operations and had a lower surface roughness than group E. However, group C's surface roughness after group $\mathrm{E}$ was higher than other groups of surface operations. 
The surface of the polished nitinol alloy had minimal roughness. This is also true for surface correction operations with Group B.

The results of cell growth and proliferation on the third day (Figure 4-a) show that the two samples $\mathrm{E}$ and $\mathrm{D}$ had a significant difference with the control nickel-titanium group $(\mathrm{n}=3$ and $\mathrm{P}<0.05)$. However, apart from the two groups mentioned, no significant difference was observed between the other groups. However, after six days of culture, the rate of cell growth and proliferation on the chemically modified nitinol memory alloy surfaces showed a significant difference with the unmodified surface.

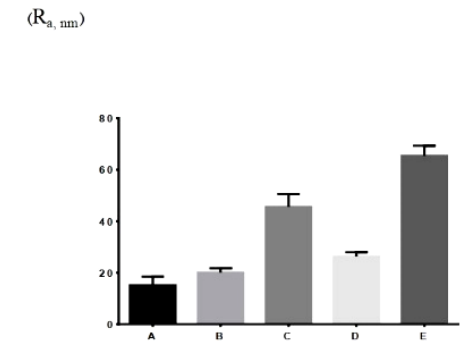

(a)

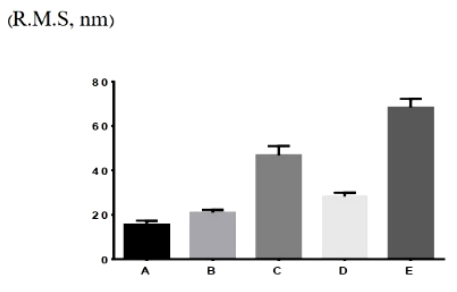

(b)

Figure 3. Surface roughness values (a): Average surface roughness (Ra) and (b) Surface roughness (RMS) of mechanically polished and chemically modified nitinol surfaces; All data are reported in terms of mean \pm Standard Error $(n=3)$.

Statistical evaluations showed that there were very high differences between groups $(\mathrm{C}$, $\mathrm{D}$, and E) with unmodified nickel-titanium level (A) ( $\mathrm{n}=3, \mathrm{P}<0.001)$. This difference is also significant between groups B and groups (C, D, and E). Still, nickel-titanium levels modified with an acidic solution of $80 \%$ hydrochloric acid, $10 \%$ fluoride acid, $10 \%$ phosphoric acid, and then chemical operations with a solution of hydrochloric and nitric acid (E), with a solution of $80 \%$ hydrochloric acid, $10 \%$ fluoride acid, $10 \%$ phosphoric acid, $1.7 \mathrm{~g}$ of calcium fluoride (D), in addition to significant differences with the control group, significant differences with chemically modified nickel-titanium levels, they had. The bar chart study shows that the control group had a decrease in cell growth and proliferation on its surface on the sixth day compared to the third day, and the bone-forming cells could not grow and proliferate on the surface. This is while all modified levels show an increase in growth and proliferation with increasing time. Except for samples E and D, which had the highest growth and proliferation rates on the third and sixth days, sample $\mathrm{C}$ on the sixth day showed a more significant increase in cell growth and proliferation on its surface than on the third day. Besides, for the two variables of Ra or RMS surface roughness and critical activity, two-factor analysis of variance was performed, and its descriptive and analytical values are presented in Table 2 and Table 3.

The results of cell adhesion (Figure 5) show that two samples (C) and (E) had the highest cell adhesion to their surface. However, the samples with the highest roughness (samples modified with $80 \%$ hydrochloric acid, 10\% fluoric acid, 10\% phosphoric acid, and then nitric acid were used as the next step) showed higher adhesion than the other samples. have given. In sample (E), which had the highest roughness at the nanoscale, this amount was maximum, and for sample (C), this amount was high. Statistical considerations showed a significant difference between sample (E) and control group ( $n=3$ and $P<0.001$ ). There was a significant difference between sample (C) and sample (B) as well as a sample (E) and sample (A) ( $\mathrm{n}=3$ and $\mathrm{P}<0.001)$. Statistical considerations also showed a significant difference between sample $(\mathrm{C})$ and group $(\mathrm{B})(\mathrm{n}=3$ and $\mathrm{P}<0.01)$. 
(a)
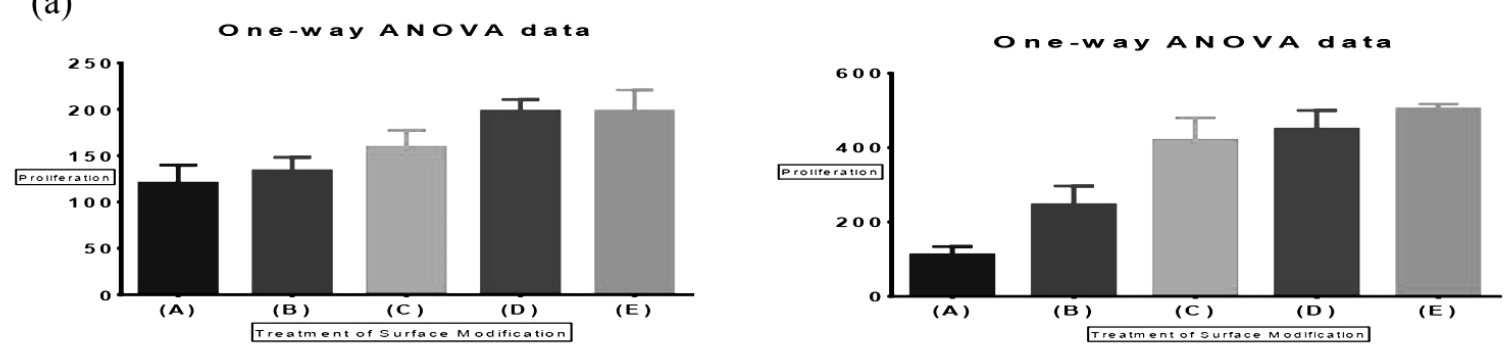

Figure 4. A vital activity of growth and proliferation of osteogenic cells on modified nickel-titanium surfaces and control group after a): three days of culture and b): six days of culture.

Table 2. The mean and standard deviation of critical activity with a variable level of surface roughness (Ra or RMS) by duration and group

\begin{tabular}{c|c|c|}
\hline Sample & $\begin{array}{c}\text { Six days } \\
\text { mean } \pm \text { Standard Error }\end{array}$ & $\begin{array}{c}\text { Three days } \\
\text { mean } \pm \text { Standard Error }\end{array}$ \\
\hline A & $\mathbf{2 1 8 . 0} \pm \mathbf{3 6 . 1 4}$ & $128.0 \pm 10.414$ \\
\hline $\mathrm{B}$ & $\mathbf{2 6 1 . 3} \pm \mathbf{2 2 . 2 6}$ & $139.7 \pm 11.260$ \\
\hline $\mathrm{C}$ & $\mathbf{4 5 4 . 0} \pm \mathbf{2 7 . 6 8}$ & $158.0 \pm 15.144$ \\
\hline $\mathrm{D}$ & $\mathbf{4 7 5 . 3} \pm \mathbf{2 3 . 2 4}$ & $202.7 \pm 11.566$ \\
\hline $\mathrm{E}$ & $\mathbf{5 1 9 . 0} \pm \mathbf{1 1 . 0 2}$ & $202.3 \pm 13.170$ \\
\hline Time & $\mathrm{F}=\mathbf{3 . 6 1}$ & $\mathrm{P}=0.237$ \\
Group & $\mathrm{F}=\mathbf{1 . 8 9}$ & $\mathrm{P}=0.520$ \\
\hline
\end{tabular}

Table 3. Mean values and standard deviation of surface operations for cell adhesion

\begin{tabular}{ccc}
\hline Group & Standard Deviation & Mean \\
\hline A & 15.275 & 123.33 \\
B & 45.092 & 153.33 \\
C & 20.526 & 272.63 \\
D & 23.629 & 208.33 \\
E & 36.056 & 310.00 \\
\hline
\end{tabular}

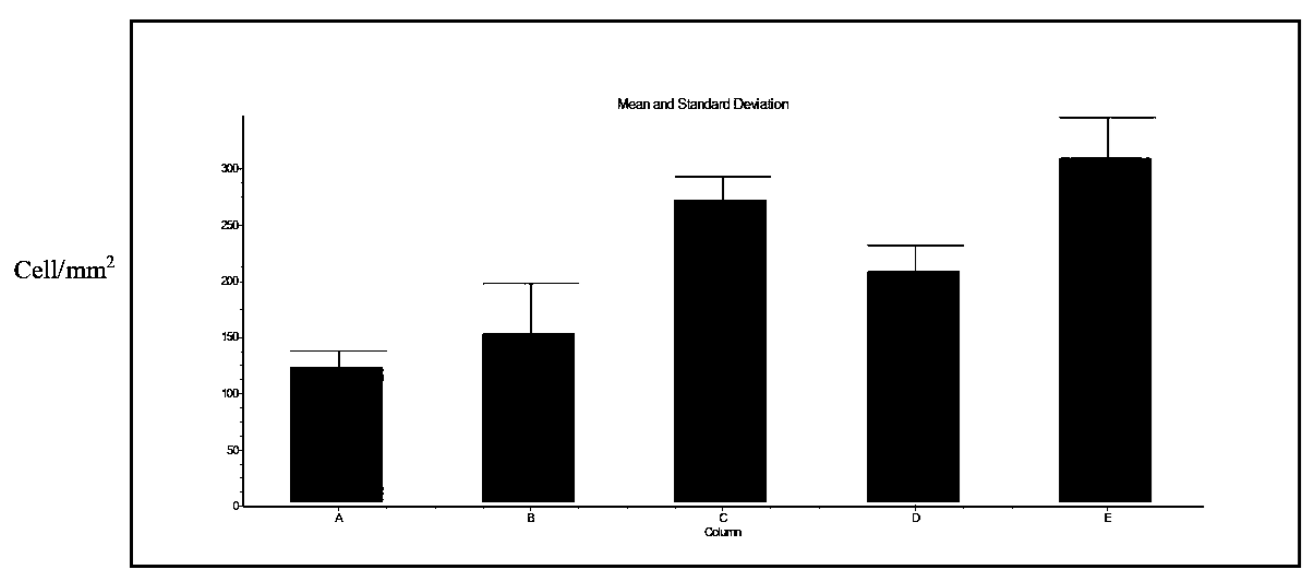

Group Surface Treatment

Figure 5. Many osteoblasts adhering to modified nickel-titanium surfaces and control groups after 16 hours of culture.

This indicates that the effect of subsequent chemical treatment with a dual-acid solution consisting of hydrochloric and nitric acid (in the presence of $\mathrm{NaCl}$ salt) will affect the surface's morphology and morphology.

The reason for this can be considered only the removal of lines due to mechanical polishing on the alloy surface and the lack of morphological changes in the alloy surface by this acidic solution (Group B). 
The use of chemical modification operations for memory alloys can change the surface morphology. The process of surface modification with a tertiary acidic solution and then applying chemical operations with nitric acid on the surface create depressions and protrusions on the micron scale (Figure 1). -c). Therefore, the role of acidic solution can be considered as a pre-treatment for surface modification because this behavior can be considered useful in adhesion and bone growth and proliferation on the surface. It should also be noted the formation of complex compounds in addition to the addition of sodium chloride to the acidic solution. Under these conditions, the surface texture has the maximum amount of depressions with uniform shapes. Exposure of nitinol to a tertiary acid solution with the causative agent of bioactive groups on the surface shown in figure (1-d) shows the combination of surfactants (tertiary acidic solution) with calcium fluoride, surface corrosion conditions And has affected the corrosion potential of the solution. Also, pores are created smaller than chemical operations with nitric acid (Figure (1-c)). As a result, from the point of view of the surface morphology of the nitinol alloy, the scanning electron microscope (1-c-d) images confirm the micron-scale cavities on the surface. These surface cavities are almost identical to each other in the form of small hemispheres, but depending on the type of acidic solution and subsequent chemical treatment on the surface, the size of these hemispheres will vary, and the morphology will change drastically. Besides, the microscopic image of the atomic force associated with this operation (Figure (2-d)) shows an intense corrosion concentration in the areas inside the surface cavities; Tiny cavities of less than a micron-scale are created on the surface. It should be noted that the presence of calcium fluoride has affected the corrosion potential of the tertiary acidic solution. Comparison of Figure (1-e) with Figures 1- (b-d) shows the presence of folds and loss of surface layers of nitinol alloy, which is due to the high corrosivity of the acidic solution. Also, the surface energy under these conditions is very high (7); So that the micro-cavities created under the action of the tertiary acidic solution are eliminated by subsequent surface operations, and the surface is smoothed. As the surface of the alloy increases in the mentioned acidic solution, it is expected that the corrosion will be out of its concentrated state, and the surface will be severely corroded. As a result, the reference surface texture is not created ( 8 , 7). Also, the highest values of surface roughness of images 3- (a-b) were related to surface operation E. This indicates the effect of subsequent chemical treatment with a dual-acid solution consisting of hydrochloric and nitric acid (in the presence of $\mathrm{NaCl}$ salt) affects surface morphology. Surface roughness at the micron scale has a significant effect on cellular activity and biomechanical properties as a result of mechanical locks between tissue and implant. The reason for this can be traced to the growth and proliferation of bone cells and tissues within the micron-scale cavities of the implant surface. Therefore, by examining the results related to adhesion and cell growth and proliferation, it was determined that sample E, which had the highest surface roughness (RMS), had significant adhesion and cell growth and proliferation. Group B also showed roughly similar surface roughness to the control group. This can be considered only the removal of lines due to mechanical polishing on the alloy surface and the lack of morphological changes in the alloy surface by this acidic solution (surface operation B).

Due to the significant effect of nitric acid in changing the surface's morphology and analyzing the interaction of this acid with the sample surface, the following chemical reactions have been described. Thus, placing the memory alloy in the $\mathrm{HNO}_{3}$ solution will cause selective corrosion of its surface. Therefore, first, the active nickel samples are dissolved on the surface 
of the material, and finally, titanium oxide is formed on the surface according to the following reaction.

$$
\begin{aligned}
& \left.3 \mathrm{Ni}+8 \mathrm{HNO}_{3}=3 \mathrm{Ni}\left(\mathrm{NO}_{3}\right)_{2}+2 \mathrm{NO}+\mathrm{H}_{2} \mathrm{O} \quad \text { (eq. } 1\right) \\
& 3 \mathrm{Ti}+4 \mathrm{HNO}_{3}+\mathrm{H}_{2} \mathrm{O}=3 \mathrm{TiO}_{2} \cdot \mathrm{H}_{2} \mathrm{O}+4 \mathrm{NO} \quad \text { (eq. 2) }
\end{aligned}
$$

Therefore, when the nitinol alloy is modified with an aqueous solution, an oxide layer of essentially $\mathrm{TiO}_{2}$ or $\mathrm{TiO}$ will form on the surface. Besides, $\mathrm{TiO}_{2}$ has better biocompatibility than $\mathrm{Ti}$, and the presence of a surface layer of $\mathrm{TiO}_{2}$ can prevent the potential release of nickel from the NiTi substrate [2]. Other studies using hydrothermal and alkaline-heat treatment to increase the bioactivity of the nitinol alloy surface Also indicate the presence of a layer of titanium oxide on the surface $[10,26]$.

The level of nitinol alloy of tertiary acidic solution $80 \%$ hydrochloric acid, $10 \%$ fluoric acid, 10\% phosphoric acid (10 minutes, ambient temperature) alone had little effect on micronscale porosity (Figure 1-b), but the tertiary acidic solution could cause failure. Oxide and titanium formation on the surface, which provided the conditions for further chemical operations and correction of the alloy's surface. Surface roughness can play an essential role in forming an apatite-like layer on the surface of biomaterials [6]. On the other hand, the extent of cavities on the surface of nitinol should be noted due to changes in acidic solution conditions. In sample D, which had the largest width in terms of surface cavities ( 0.5 to 7 microns), significant cell growth and proliferation was observed. However, other morphological studies have considered a surface with pore sizes of 6 to 10 microns or 0.5 to 2 microns as the ideal surface for cell growth and proliferation [19, 20, 27]. The surface showed a higher value for nitinol groups modified with nitric acid, which can be attributed to a further increase in surface roughness due to this acid's percentage [21]. It should be noted that the morphological role of surface cavities is also of particular importance in cell growth and proliferation. Also, fibrous tissue (fibrous capsule) that prevents the bone from coming into direct contact with the implant was formed.

In general, about two decades ago, studies began to expand non-coated titanium surfaces. Surface microtopography can affect the number and morphology of cell adhesive legs and the orientation of cells (osteoblasts) and direct cell migration into cavities in the implant surface, thereby increasing bone growth. This can be related to the implant's surface energy; in other words, the degree of hydrophilicity of the surface $[6,7,28]$. Therefore, surface wettability has also been suggested for higher adhesion of proteins. Protein adhesion prepares the migration of bone-forming cells across the surface. Therefore, in the E sample, which had the highest surface roughness, higher adhesion, cell growth, and proliferation can be expected compared to other samples. From the above, it can be reported that surface roughness and chemistry play a significant role in cell behavior on the implant surface. Fibronectin is a glycoprotein that adheres rapidly to hard surfaces, resulting in adhesion to other cells and creates a closer stoichiometry of the ratio of calcium to phosphate (1.55) in the apatite-like bone coating on its surfaces [6,29].

Titanium implants are highly active against fluoride ions and form titanium tetrafluoride. The produced surface has a topography with micron roughness. However, acidic operations such as fluoride acid can create nanoscale topographies, typically as structures with at least one dimension within one to one hundred nanometers [7]. In addition to creating a rough surface, these chemical operations lead to the presence of fluoride ions on the titanium 
surface, which combine to bind the implanted titanium bone to the bone tissue $[7,31,32]$. This was not observed for the nitinol alloy; Because nickel has good corrosion resistance to fluorine ions. However, the use of chemical treatments with nitric acid can modify the nitinol alloy in terms of surface morphology and alteration of the oxide layer [33]. The chemical surface modification increases the dissociation of ossifying cells compared to unmodified specimens. This process can also provide the potential for a greater improvement of the implant base in the bone by providing a bioactive implant surface.

\section{Conclusions}

The nitinol alloy's surface shows significant changes when exposed to an acidic solution consisting of tertiary acids $\left(\mathrm{HCl}-\mathrm{HF}-\mathrm{H}_{3} \mathrm{PO}_{4}\right)$ with subsequent chemical treatment with nitric acid. This leads to micron-scale cavities on the surface. Nitric acid is very effective in causing cavities on the micron scale. In addition to nitric acid, which is primarily responsible for creating roughness on the titanium surface, hydrochloric acid also changes the surface morphology. In general, cell culture evaluations showed that the use of acidic solution consisting of tertiary acids $\left(\mathrm{HCl}-\mathrm{HF}-\mathrm{H}_{3} \mathrm{PO}_{4}\right)$ combined with subsequent chemical treatment with nitric acid increases the ability of nitinol levels in adhesion and cell growth and proliferation. Therefore, chemical operations are an easy way to bioactivate the surface of a nitinol alloy. This study's results are based on experiments outside the body but can show similar results to tests inside the body.

\section{Funding}

This research received no external funding.

\section{Acknowledgments}

The authors of the article consider it necessary to thank the Vice Chancellor for Research of Tehran University of Medical Sciences, Faculty of Materials Engineering and Metallurgy of Amirkabir University of technology, Bionano Bioactive Materials Research Group of Amirkabir University of technology, and Karaj Materials and Energy Research Institute for supporting this article.

\section{Conflicts of Interest}

The authors declare no conflict of interest.

\section{References}

1. Jin, J.; Zhou, S.; Zhao, Y.; Zhang, Q.; Wang, X.; Li, W.; Chen, D.; Zhang, L.-C. Refined microstructure and enhanced wear resistance of titanium matrix composites produced by selective laser melting. Optics \& Laser Technology 2021, 134, https://doi.org/10.1016/j.optlastec.2020.106644.

2. Xiang, K.; Chai, L.; Wang, Y.; Wang, H.; Guo, N.; Ma, Y.; Murty, K.L. Microstructural characteristics and hardness of CoNiTi medium-entropy alloy coating on pure Ti substrate prepared by pulsed laser cladding. Journal of Alloys and Compounds 2020, 849, https://doi.org/10.1016/j.jallcom.2020.156704.

3. Ali, M.A.; Naqib, S.H. Recently synthesized (Ti1-xMox)2AlC $(0 \leq x \leq 0.20)$ solid solutions: deciphering the structural, electronic, mechanical and thermodynamic properties via ab initio simulations. RSC Advances 2020, 10, 31535-31546, https://doi.org/10.1039/D0RA06435A.

4. Liu, S.; Zhang, X.; Peng, H.-L.; Han, X.; Yang, H.-Y.; Li, T.-T.; Zhu, L.; Zhang, S.; Qiu, F.; Bai, Z.-H.; Chen, S.-M.; Zhou, W.; Jiang, Q.-C. In situ nanocrystals manipulate solidification behavior and microstructures of hypereutectic Al-Si alloys by Zr-based amorphous alloys. Journal of Materials Research and Technology 2020, 9, 4644-4654, https://doi.org/10.1016/j.jmrt.2020.02.091. 
5. Xie, L.; Guo, H.; Song, Y.; Liu, C.; Wang, Z.; Hua, L.; Wang, L.; Zhang, L.-C. Effects of electroshock treatment on microstructure evolution and texture distribution of near- $\beta$ titanium alloy manufactured by directed energy deposition. Materials Characterization 2020, 161, https://doi.org/10.1016/j.matchar.2020.110137.

6. Li, Y.; Song, P.; Wang, W.; Lei, M.; Li, X. Microstructure and wear resistance of a Ni-WC composite coating on titanium grade 2 obtained by electroplating and electron beam remelting. Materials Characterization 2020, 170, https://doi.org/10.1016/j.matchar.2020.110674.

7. Liu, S.; Han, S.; Zhang, L.; Chen, L.-Y.; Wang, L.; Zhang, L.; Tang, Y.; Liu, J.; Tang, H.; Zhang, L.-C. Strengthening mechanism and micropillar analysis of high-strength NiTi-Nb eutectic-type alloy prepared by laser powder bed fusion. Composites Part B: Engineering 2020, 200, https://doi.org/10.1016/j.compositesb.2020.108358.

8. Singh, N.; Hameed, P.; Ummethala, R.; Manivasagam, G.; Prashanth, K.G.; Eckert, J. Selective laser manufacturing of Ti-based alloys and composites: impact of process parameters, application trends, and future prospects. Materials Today Advances 2020, 8, https://doi.org/10.1016/j.mtadv.2020.100097.

9. Liang, S.-X.; Zhang, Q.; Jia, Z.; Zhang, W.; Wang, W.; Zhang, L.-C. Tailoring surface morphology of heterostructured iron-based Fenton catalyst for highly improved catalytic activity. Journal of Colloid and Interface Science 2021, 581, 860-873, https://doi.org/10.1016/j.jcis.2020.07.138.

10. Zhu, Y.S.; Yin, Y.X.; Wu, J.; Liu, Y.F.; Lu, W.; Zuo, D.; Xiao, H.; Cao, D.; Ko, T.J. Effect of RE on accelerating the kinetics of boride layer growth on titanium alloy. Journal of Alloys and Compounds 2020, 844, https://doi.org/10.1016/j.jallcom.2020.156091.

11. Jawed, S.F.; Liu, Y.J.; Wang, J.C.; Rabadia, C.D.; Wang, L.Q.; Li, Y.H.; Zhang, X.H.; Zhang, L.C. Tailoring deformation and super-elastic behaviors of beta-type Ti-Nb-Mn-Sn alloys. Journal of the Mechanical Behavior of Biomedical Materials 2020, 110, https://doi.org/10.1016/j.jmbbm.2020.103867.

12. Yang, H.; Yue, X.; Wang, Z.; Shao, Y.; Shu, S. Strengthening mechanism of TiC/Al composites using AlTi-C/CNTs with doping alloying elements $(\mathrm{Mg}, \mathrm{Zn}$ and $\mathrm{Cu})$. Journal of Materials Research and Technology 2020, 9, 6475-6487, https://doi.org/10.1016/j.jmrt.2020.04.033.

13. Rabadia, C.D.; Liu, Y.J.; Jawed, S.F.; Wang, L.Q.; Sun, H.; Zhang, L.C. Deformation and toughness behavior of $\beta$-type titanium alloys comprising C15-type Laves phase. Materials Today Sustainability 2020, 9, https://doi.org/10.1016/j.mtsust.2020.100034.

14. Wang, L.; Wang, Y.; Huang, W.; Liu, J.; Tang, Y.; Zhang, L.; Fu, Y.; Zhang, L.-C.; Lu, W. Tensile and super-elastic behaviors of Ti-35Nb-2Ta-3Zr with gradient structure. Materials \& Design 2020, 194, https://doi.org/10.1016/j.matdes.2020.108961.

15. Dziaduszewska, M.; Shimabukuro, M.; Seramak, T.; Zielinski, A.; Hanawa, T. Effects of Micro-Arc Oxidation Process Parameters on Characteristics of Calcium-Phosphate Containing Oxide Layers on the Selective Laser Melted Ti13Zr13Nb Alloy. Coatings 2020, 10, https://doi.org/10.3390/coatings10080745.

16. da Silva, M.; Gargarella, P.; Plaine, A.; Contieri, R.; Pauly, S.; Kühn, U.; Bolfarini, C. Influence of the deformation rate on phase stability and mechanical properties of a $\mathrm{Ti}-29 \mathrm{Nb}-13 \mathrm{Ta}-4.6 \mathrm{Zr}-\mathrm{x} \mathrm{O}$ alloy analyzed by in situ high-energy X-ray diffraction during compression tests. Journal of Materials Research 2020, 113, https://doi.org/10.1557/jmr.2020.150.

17. Dai, J.; Xia, J.; Chai, L.; Murty, K.L.; Guo, N.; Daymond, M.R. Correlation of microstructural, textural characteristics and hardness of Ti-6Al-4V sheet $\beta$-cooled at different rates. Journal of Materials Science 2020, 55, 8346-8362, https://doi.org/10.1007/s10853-020-04603-9.

18. Ahirwar, H.; Zhou, Y.; Mahapatra, C.; Ramakrishna, S.; Kumar, P.; Nanda, H.S. Materials for Orthopedic Bioimplants: Modulating Degradation and Surface Modification Using Integrated Nanomaterials. Coatings 2020, 10, https://doi.org/10.3390/coatings10030264.

19. Zhang, Y.; Li, J.; Jiang, Y.; Kang, D.; Juan, Y.; Lu, Z. Investigation into corrosion and wear behaviors of laser-clad coatings on Ti6Al4V. Materials Research Express 2020, 7, https://doi.org/10.1088/20531591/ab6a53.

20. Wang, Z.-X.; Zhang, J.-W.; Ye, F.; Lv, W.-G.; Lu, S.; Sun, L.; Jiang, X.-Z.; Properties of Micro-Arc Oxidation Coating Fabricated on Magnesium Under Two Steps Current-Decreasing Mode. Frontiers in Materials 2020, 7, https://doi.org/10.3389/fmats.2020.00261.

21. Cheng, J.; Wang, H.; Li, J.; Gai, J.; Ru, J.; Du, Z.; Fan, J.; Niu, J.; Song, H.; Yu, Z.; The Effect of Cold Swaging Deformation on the Microstructures and Mechanical Properties of a Novel Metastable $\beta$ Type Ti$10 \mathrm{Mo}-6 \mathrm{Zr}-4 \mathrm{Sn}-3 \mathrm{Nb}$ Alloy for Biomedical Devices. Frontiers in Materials 2020, 7 , https://doi.org/10.3389/fmats.2020.00228.

22. Chen, L.-Y.; Cui, Y.-W.; Zhang, L.-C. Recent Development in Beta Titanium Alloys for Biomedical Applications. Metals 2020, 10, https://doi.org/10.3390/met10091139.

23. Alluaibi, M.H.; Cojocaru, E.M.; Rusea, A.; Șerban, N.; Coman, G.; Cojocaru, V.D. Microstructure and Mechanical Properties Evolution during Solution and Ageing Treatment for a Hot Deformed, above $\beta$ transus, Ti-6246 Alloy. Metals 2020, 10, https://doi.org/10.3390/met10091114.

24. Zang, Q.; Li, X.; Chen, H.; Zhang, J.; Wang, L.; Chen, S.; Jin, Y.; Lu, S.; Microstructure and Mechanical Properties of AZ31/ZrO2 Composites Prepared by Friction Stir Processing With High Rotation Speed. Frontiers in Materials 2020, 7, https://doi.org/10.3389/fmats.2020.00278. 
25. Zheng, Z.; Chai, L.; Xiang, K.; Huang, W.; Wang, Y.; Liu, L.; Tian, L. Typical Microstructural Characteristics of $\mathrm{Ti}-5 \mathrm{Al}-5 \mathrm{Mo}-5 \mathrm{~V}-3 \mathrm{Cr}-1 \mathrm{Fe}$ Metastable $\beta$ Ti Alloy Forged in $\alpha+\beta$ Region. Acta Metallurgica Sinica (English Letters) 2020, 33, 1601-1608, https://doi.org/10.1007/s40195-020-01115-y.

26. Pei, C.G.; Guo, Z.X.; Xiao, J.G. Effect of laser remelting treatment on A185Ni8Y4Ce3 amorphous coating. Surface Engineering 2020, 1-8, https://doi.org/10.1080/02670844.2020.1800347.

27. Okulov, I.V.; Joo, S.-H.; Okulov, A.V.; Volegov, A.S.; Luthringer, B.; Willumeit-Römer, R.; Zhang, L.; Mädler, L.; Eckert, J.; Kato, H. Surface Functionalization of Biomedical Ti-6Al-7Nb Alloy by Liquid Metal Dealloying. Nanomaterials 2020, 10, https://doi.org/10.3390/nano10081479.

28. Wang, Z.-X.; Xu, L.; Zhang, J.-W.; Ye, F.; Lv, W.-G.; Xu, C.; Lu, S.; Yang, J.; Preparation and Degradation Behavior of Composite Bio-Coating on ZK60 Magnesium Alloy Using Combined Micro-Arc Oxidation and Electrophoresis Deposition. Frontiers in Materials 2020, 7, https://doi.org/10.3389/fmats.2020.00190.

29. Xiao, F.; Xiang, J.; Cheng, G.; Jiang, Z.; Osaka, A.; Ma, X.-c. In situ fabrication of anatase thin films with high percentage of exposed $\{001\}$ facets to improve biocompatibility with MC3T3-E1 cells. Journal of Materials Science 2020, 55, 14008-14018, https://doi.org/10.1007/s10853-020-04957-0.

30. Fan, J.; Huang, H.; Xue, X.; Zhang, W.; Wang, Y.; Zhang, B.; Tang, B.; Zhao, R.; Kou, H.; Li, J. Hot Rolled Ti6321 Alloy Sheets With Different Initial Microstructures: Microstructure, Mechanical Properties, and Anisotropy Characteristics. Frontiers in Materials 2020, 7.

31. Cheng, J.; Li, J.; Yu, S.; Du, Z.; Zhang, X.; Gai, J.; Fan, J.; Zhang, W.; Song, H.; Yu, Z.; Room Temperature Deformation and Super-elastic Behavior of TLM Titanium Alloy Under Different Solution Conditions. Frontiers in Materials 2020, 7, https://doi.org/10.3389/fmats.2020.00114.

32. Cheng, J.; Li, J.; Yu, S.; Du, Z.; Zhang, X.; Zhang, W.; Gai, J.; Wang, H.; Song, H.; Yu, Z.; Cold Rolling Deformation Characteristic of a Biomedical Beta Type Ti-25Nb-3Zr-2Sn-3Mo Alloy Plate and Its Influence on $\alpha$ Precipitated Phases and Room Temperature Mechanical Properties During Aging Treatment. Frontiers in Bioengineering and Biotechnology 2020, 8, https://doi.org/10.3389/fbioe.2020.598529.

33. Qiu, Z.; Wang, L.; Wu, J.; Wang, L.; Li, Z.; Xu, Z.; Li, W.; Gui, T.; Study the synthesis and the properties of self-crosslinking acrylic latex via a novel fluorescent labeling method. Journal of Applied Polymer Science 2020, https://doi.org/10.1002/app.49973. 